\title{
Active Rifting Structures in Iheya Graben and Adjacent Area of the Mid-Okinawa Trough Observed Through Seismic Reflection Surveys
}

\author{
Fumihiko Ikegami, Takeshi Tsuji, Hidenori Kumagai, \\ Jun-ichiro Ishibashi, and Ken Takai
}

\begin{abstract}
The mid-Okinawa Trough is recognized as an area with extensive volcanism and hydrothermal activity. The Iheya Graben is a depression in the mid-Okinawa Trough, extending approximately $100 \mathrm{~km}$ in an ENE-WSW strike. The graben lies $200 \mathrm{~m}$ below the surrounding flat-surfaced trough floor (from $-1,400$ to $-1,600 \mathrm{~m}$ below sea level). The latest seismic profiles in the western Iheya Graben and adjacent areas reveal numerous normal faults, possibly in association with the rifting activity of the Okinawa Trough. The faulting of the Iheya Graben is non-listric syn-depression faulting, in contrast with dense listric faulting of the adjacent trough floor. The faulting in both areas consists of numerous seafloor-reaching active faults; however, recent activity is concentrated within the Iheya Graben. Non-listric faulting in the Iheya Graben shapes its present structure with large displacements. The displacements and fault propagations indicate the depression of the Iheya Graben was created with an abrupt flexural subsidence followed by extension with normal faulting. The event occurred largely before the formation of the overlying Iheya Ridge, which was reported to be at least $0.2 \mathrm{Ma}$. Such a significant event may be related to the present extensive volcanism in the region by means of rifting tectonics and magmatism.
\end{abstract}

\section{Keywords}

Back-arc basin • Okinawa Trough $•$ Rifting $\bullet$ Seismic reflection survey

F. Ikegami $(\bowtie)$

Graduate School of Sciences, Kyushu University,

6-10-1 Hakozaki, Higashi-ku, Fukuoka 812-8581, Japan

e-mail: ikegami@kyudai.jp

T. Tsuji

International Institute for Carbon-Neutral Energy Research (I2CNER),

Kyushu University, 744 Motooka, Nishi-ku, Fukuoka 819-0395, Japan

Submarine Resources Research Project (SRRP),

Japan Agency for Marine-Earth Science and Technology (JAMSTEC),

2-15 Natsushima-Cho, Yokosuka 237-0061, Japan

H. Kumagai

R\&D Center for Submarine Resources, Japan Agency for Marine-Earth

Science and Technology (JAMSTEC), 2-15 Natsushima-Cho,

Yokosuka 237-0061, Japan

Institute for Research on Earth Evolution (IFREE), Japan Agency

for Marine-Earth Science and Technology (JAMSTEC), 2-15

Natsushima-Cho, Yokosuka 237-0061, Japan

Precambrian Ecosystem Laboratory, Japan Agency for Marine-Earth

Science and Technology (JAMSTEC), 2-15 Natsushima-cho,

Yokosuka 237-0061, Japan

J.-i. Ishibashi

Faculty of Sciences, Kyushu University,

6-10-1 Hakozaki, Higashi-ku, Fukuoka 812-8581, Japan

Submarine Resources Research Project (SRRP),

Japan Agency for Marine-Earth Science and Technology (JAMSTEC), 2-15 Natsushima-Cho, Yokosuka 237-0061, Japan

K. Takai

Department of Subsurface Geobiological Analysis and Research (D-SUGAR) and Research and Development (R\&D), Center

for Submarine Resources, Japan Agency for Marine-Earth Science and Technology (JAMSTEC), 2-15 Natsushima-Cho,

Yokosuka 237-0061, Japan 


\subsection{Introduction}

The Okinawa Trough (Fig. 28.1a) is a NE-SW elongated back-arc basin located behind the Ryukyu Arc in the East China Sea. The Ryukyu Arc marks the convergent margin of the Eurasia and Philippine Sea Plates. The mid-Okinawa Trough is situated at the transitional settings between the shallow northern Okinawa Trough and the deep southern Okinawa Trough (Fig. 28.1a), in association with the occurrences of en echelon aligned intra-trough "grabens" (Kimura 1990). One such feature is the Iheya Graben (Iheya Depression/Iheya Deep (Ueda et al. 1985; Kimura et al. 1987)), an ENE-WSW elongated depression situated at the mid-Okinawa Trough (Fig. 28.1c). The Iheya Graben is $100 \mathrm{~km}$ long and $200 \mathrm{~m}$ deep when compared with the adjacent trough floor (Fig. 28.1c). Numerous volcanic knolls and active hydrothermal sites are distributed along the Iheya Graben and its vicinities, including the Iheya-North Knoll, the CLAM site of Iheya Ridge, and the Izena Hole (Glasby and Notsu 2003). Sibuet et al. (1987) inferred that the migration of the volcanic front into the back-arc basin resulted such an extensive volcanism in the region.

The Okinawa Trough is considered to be the only present representation of a submerged marginal rift in the nascent stage (Letouzey and Kimura 1986). However, the detailed structure and evolution of the Okinawa Trough still remains unveiled. Several seismic studies have been conducted since the 1970s to investigate these questions (Lee et al. 1980; Letouzey and Kimura 1986), however the recent surveys with modern advanced equipments were only conducted at the southern part of the Okinawa Trough (Furukawa et al. 1991; Sibuet et al. 1998; Park et al. 1998). Recent implications with other approaches such as geomagnetic (Miki 1995), paleostress (Otubo and Hayashi 2003), and coral reef studies (Iryu et al. 2006) indicate that the Okinawa Trough has experienced geographically heterogenetic evolution in multiple stages (Ishibashi et al., Chap. 27). Using the latest seismic reflection data, this study investigates the geological structures within the mid-Okinawa Trough in order to understand the evolution of the Okinawa Trough back-arc basin.

\subsection{Data}

In the 2000s, a number of seismic reflection surveys were conducted in the mid-Okinawa Trough in order to characterize the sedimentary and hydrogeologic structures of this region (Tsuji et al. 2012). In this study, four seismic profiles (Table 28.1) were used to investigate the geological structure of the Iheya Graben $(<-1,600 \mathrm{~m}$ below sea level) and adjacent trough floor (from $-1,400$ to $-1,600 \mathrm{~m}$ below sea level; Fig. 28.1c). The longest seismic profile, "Line 1" (Fig. 28.2), transects the trough floor and the Iheya graben, and was obtained on the KY02-11 cruise. The "INH10-A2" seismic profile (Fig. 28.3) transects the northern trough floor, and was obtained with a large-volume source on the KR1002 cruise, which passes through the flat-surfaced area near the Iheya-North Knoll (Fig. 28.3). Two parallel cross sections, "Line 6" and "Line 7" (Fig. 28.4), describe the Iheya Ridge, and were obtained on the YK12-16 cruise.

\subsection{Results}

\subsubsection{Iheya Graben}

The Iheya Graben appears as an ENE-WSW elongated depression within the trough floor (Fig. 28.1). At the center of the depression, the Iheya Ridge (Fig. 28.1c) extends for more than $15 \mathrm{~km}$. Three stratigraphic units: IHG-A, IHG-B, and IHG-C in descending order were defined using the seismic profiles of Line 6 and 7 (Fig. 28.4). The topmost unit, IHG-A, is an onlapping unit with weak-amplitude stratified reflectors. It has a maximum thickness of $\sim 0.27 \mathrm{~s}$ in acoustic two-way travel time. This thickness is equivalent to $\sim 200 \mathrm{~m}$ when the acoustic velocity is set at $1,500 \mathrm{~m} /$ $\mathrm{s}$ (Fig. 28.4e, f). The second unit, IHG-B, has similar weak-amplitude stratified facies, although its reflectors are dipping towards the center of the depression (Fig. 28.4c, d). The transition of such geometries between IHG-A and IHGB marks an unconformity seen in Line 7 (Fig. 28.4c), and is more subtly expressed in Line 6 (Fig. 28.4d). The lowermost IHG-C is an acoustic basement in the depression, the top of which is defined by the basal strong reflectors highlighted by the dashed line (Fig. 28.4c-f).

Faulting in the Iheya Graben is divided into two groups depending upon whether it cuts the IHG-A unit. The former are seafloor-reaching active faults, which cut both IHG-B and IHG-A units, and generate large displacement (up to tens of meters) on the seafloor (Fig. 28.4c, d). The latter, however, are the inactive counterpart and cut only the IHG$\mathrm{B}$ unit and below. Although the latter did not cause displacement in the IHG-A, some reflector hiatuses are seen in the IHG-A unit (Fig. 28.4c). Most of the faulting occurs as nonlistric normal faults, although compressional features consisting of multiple reverse faults are observed in the southern edge of the Iheya Graben (Fig. 28.4e, f).

\subsubsection{Trough Floor}

The trough floor is characterized by flat-surfaced thick deposits, and is divided north to south by the Iheya Graben (Fig. 28.1). The northern part of the trough floor lies west 

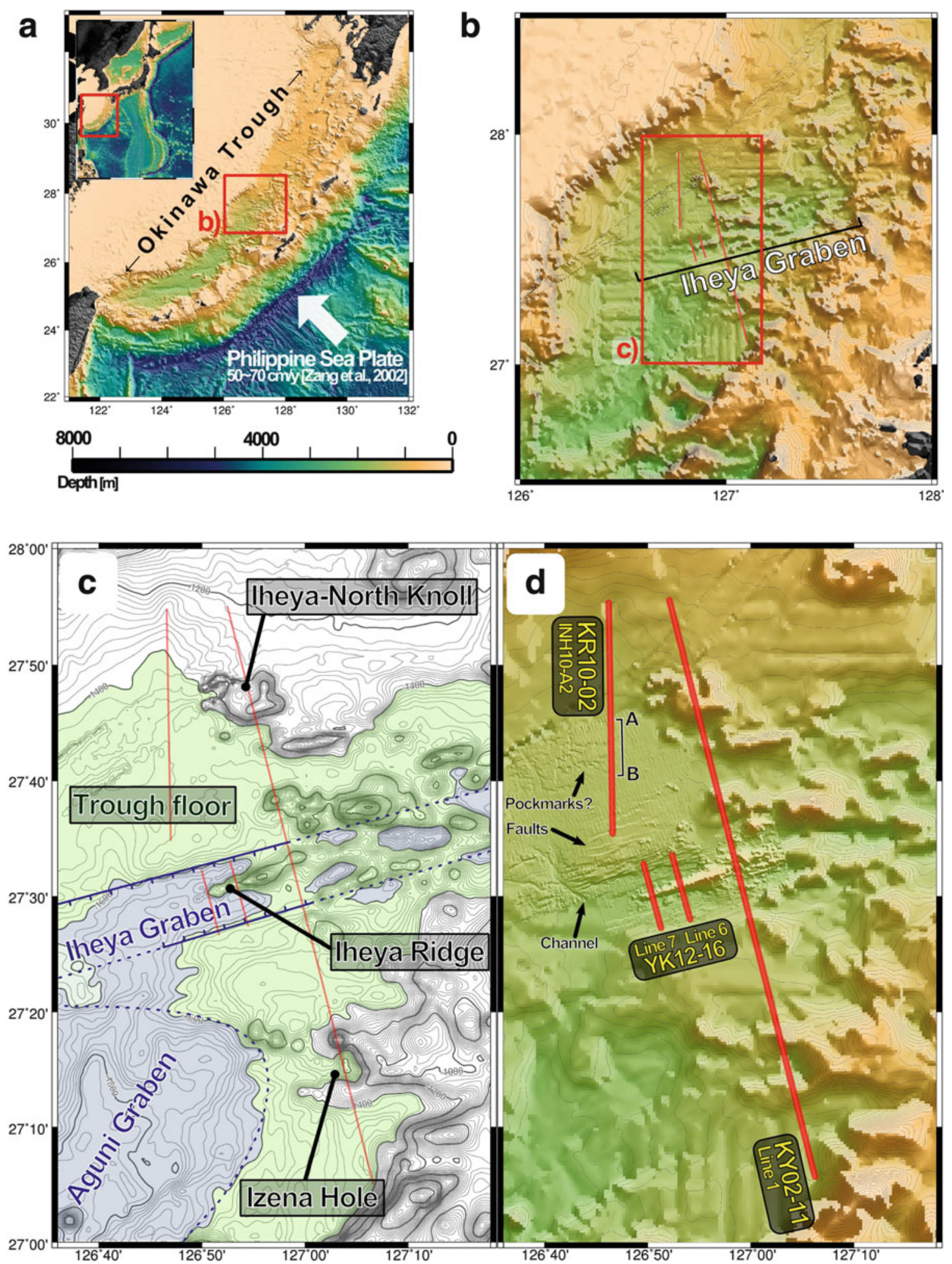

Fig. 28.1 (a) Geographical setting of the Okinawa Trough. Basemaps are from Global Multi-Resolution Topography (Ryan et al. 2009). (b) An enlarged bathymetry map of the mid-Okinawa Trough. The red box shows the survey area of this study. (c) Contoured bathymetry map with geological features highlighted. The green area is the flat-surfaced trough floor, which is bounded by the trough edge on the $-1,400 \mathrm{~m}$ contour line. The blue areas are depressions in the trough floor that are lower than $-1,600 \mathrm{~m}$. (d) Shaded bathymetry map with high-resolution data in the western Iheya Graben (Kumagai 2012). The red lines are the seismic profiles used in this study. The section A-B along the INH10A2 profile highlights where the profile intersects pockmark-like structures, and corresponds to the A-B section in Fig. 28.3 
Table 28.1 List of survey cruises and equipment used for seismic data acquisition

\begin{tabular}{llll}
\hline & Fig. 28.2 & Fig. 28.3 & Fig. 28.4 \\
\hline Year & 2002 & 2010 & 2012 \\
\hline Cruise & KY02-11 & KR10-02 & YK12-16 \\
\hline Lines & Line 1 & INH10-A2 & Line 6 and 7 \\
\hline Vessel & R/V Kaiyo & R/V Kairei & R/V Yokosuka \\
\hline Streamer & $24 \mathrm{ch} / 600 \mathrm{~m}$ & $360 \mathrm{ch} / 4,500 \mathrm{~m}$ & Single channel \\
\hline Source & $\sim 2.5 \mathrm{~L}(150 \mathrm{cu} \mathrm{in})$ & $\sim 54 \mathrm{~L}(3,300 \mathrm{cu}$ in $)$ & $\sim 2.5 \mathrm{~L}(150 \mathrm{cu}$ in $)$ \\
\cline { 2 - 4 } & G-I gun & Tuned gun & G-I gun \\
\hline
\end{tabular}

of the Iheya-North Knoll (Fig. 28.1c). Although Line 1 transects the Iheya-North Knoll, this portion of the profile did not provide detailed subsurface structures for the area possibly because of numerous volcanics, which attenuate the acoustic wave energy (Fig. 28.2a, b). However, the INH10-A2 survey, located $\sim 15 \mathrm{~km}$ west of the volcanic area (Fig. 28.1), was conducted with a large volume source, and it provided a detailed subsurface image (Fig. 28.3; Tsuji et al. 2012). The southern part of the trough floor features the Iheya and Aguni Grabens,

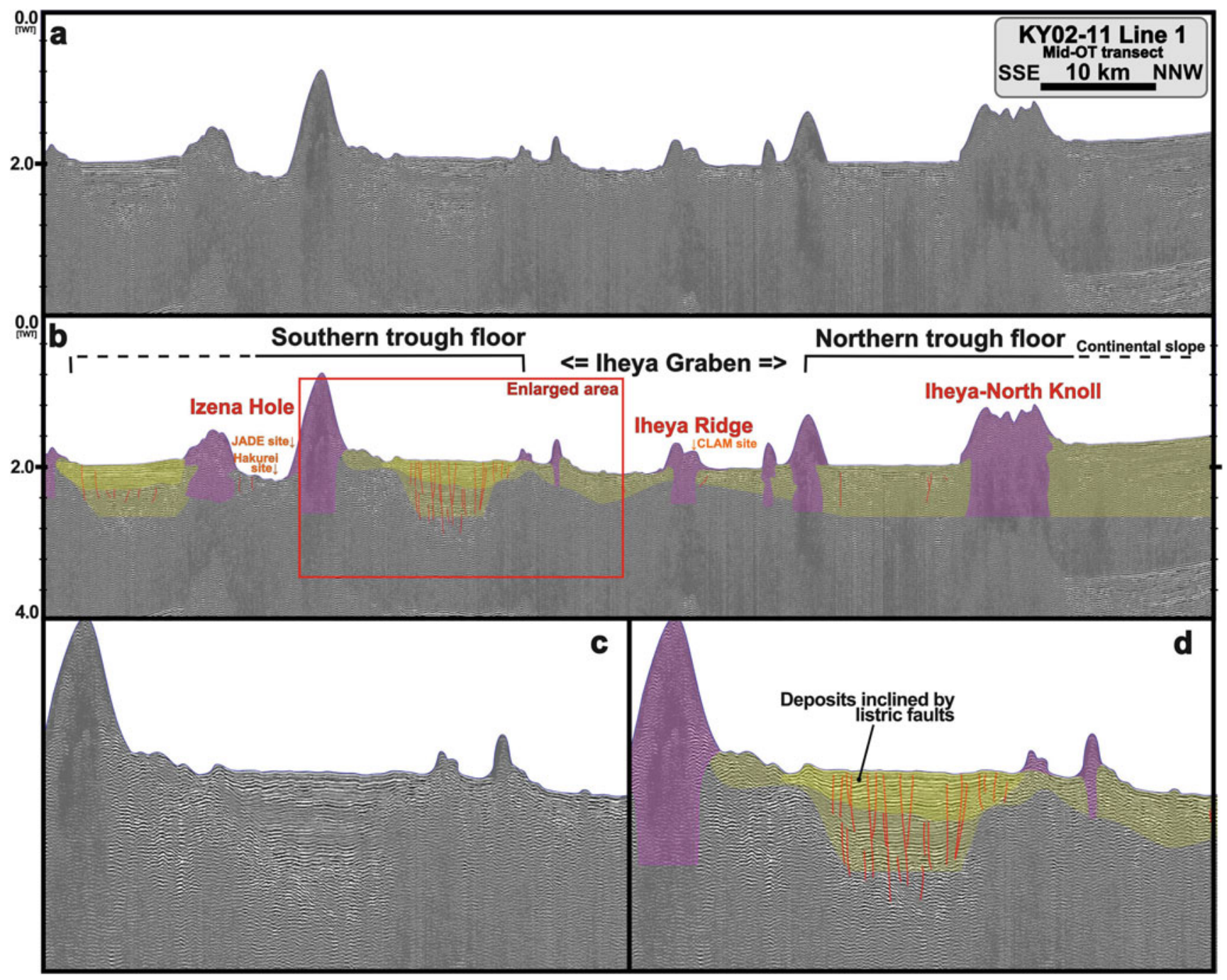

Fig. 28.2 (a) SSE-NNW seismic profile transecting the mid-Okinawa Trough obtained on the KY02-11 cruise. (b) Interpretation of the profile. The purple areas represent volcanic edifices, while the yellow areas show the approximate location of the stratified deposits. The onlapping deposits are emphasized in dark yellow. The red and orange labels show the approximate position of previously known volcanic and hydrothermal sites. (c) An enlarged image of the southern trough floor basin. (d) An interpretation of the enlarged image of the southern trough floor basin. The red lines highlight the fault planes of listric normal faults, which have cut and slightly rotated the stratified deposits 


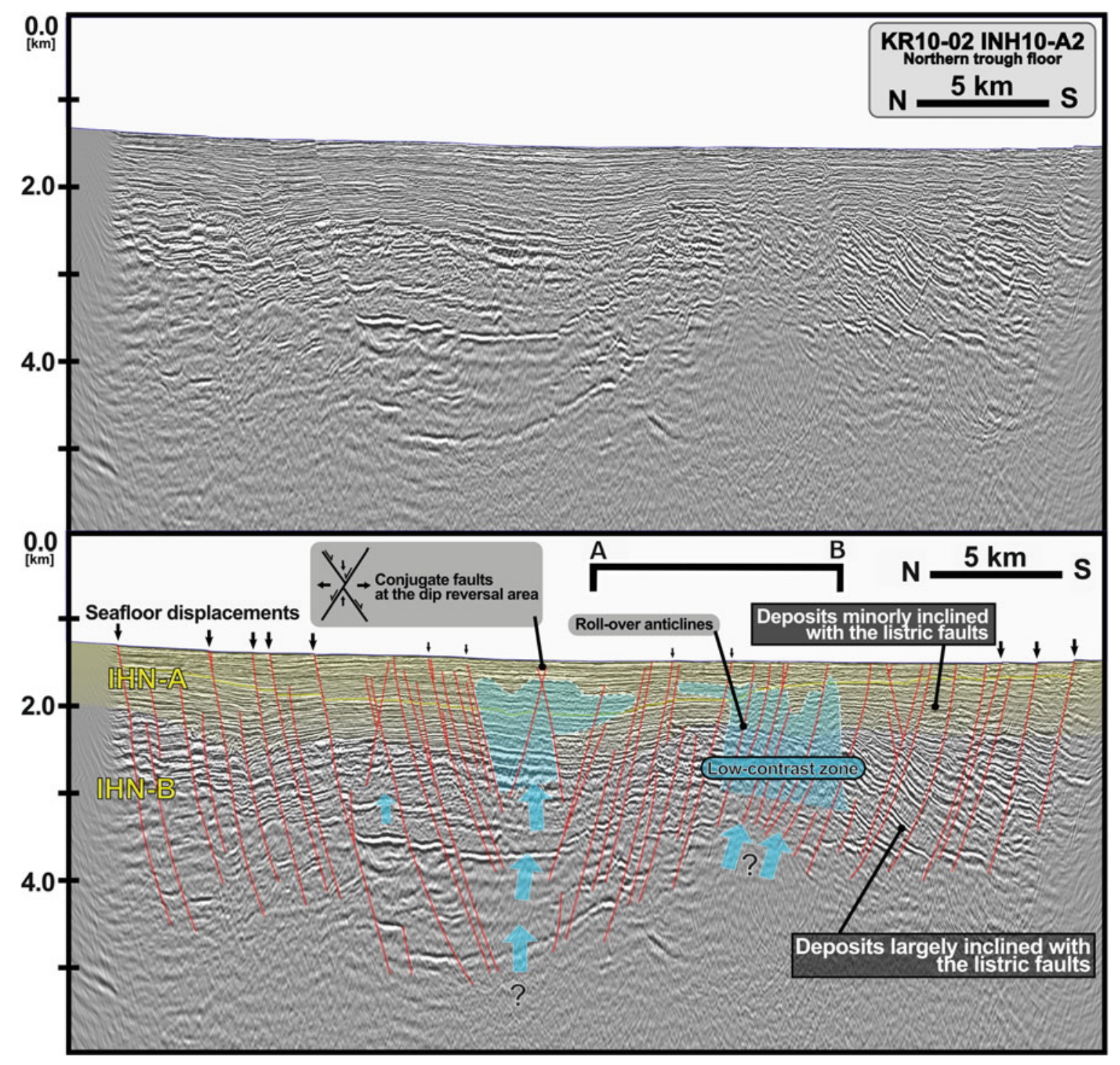

Fig. 28.3 Large volume sourced seismic profile of the northern flatsurfaced trough floor obtained on the KR10-A2 cruise (Tsuji et al. 2012). The yellow fill highlights poorly inclined recent deposits (IHN-
A), while the red lines highlight listric normal faults. The blue regions and blue arrows are fluid-indicative anomalous low-contrast zones located below the A-B section shown in Fig. 28.1c and was transected by the southern portion of Line 1 (Fig. 28.2c, d).

The depth-migrated seismic profile of the INH10-A2 line (Fig. 28.3) in the northern trough floor shows thick stratified deposits that were cut and inclined by densely spaced listric normal faults. The dips of those faults reverse at the center of the profile, forming a conjugate fault system, where the profile is neighboring the Iheya-North Knoll. The deposits are divided into IHN-A and IHN-B based on the change in degree of inclination. The reflectors in the upper IHN-A are almost parallel to the seafloor, while the reflectors in IHN-B increase their inclination along the depth. The reflectors in both IHN-A and B deposits often become ambiguous in multiple kilometer-scale "low-contrast zones," which strongly indicate the presence of fluid activity in the region, as previously reported by Tsuji et al. (2012).

Meanwhile, the resolution of the Line 1 did not allow for precise examination of the subsurface structures of the southern trough floor, it is similar to its northern counterpart with thick stratified deposits that are cut and inclined with numerous listric faults. The dip-reversal occurs at the center of the basin as well. The inclination of the southern trough floor deposits are small and uniform throughout the top to bottom of the deposits. 


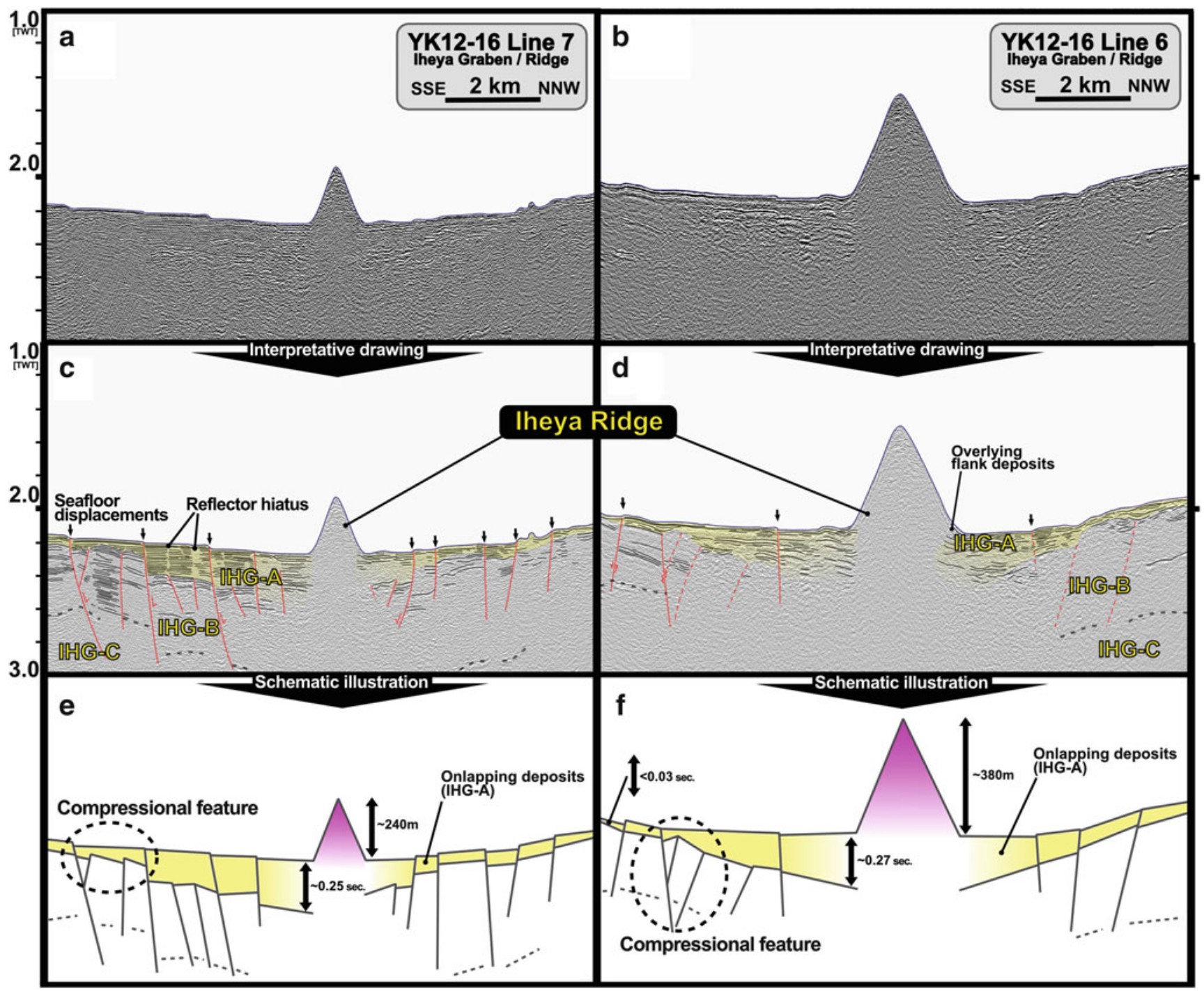

Fig. 28.4 (a, b) SSE-NNW single-channel seismic cross-sections in the western Iheya Graben obtained on the YK12-16 Cruise (Kumagai 2012). The knoll in the center of each section is the Iheya Ridge, which is located at the center of the Iheya Graben. (c, d) Interpretative drawings of the previous images. The onlapping facies (IHG-A) are

\subsection{Discussion}

\subsubsection{Structure of the Iheya Graben and Adjacent Trough Floor}

The geologically prominent feature in the survey area of the Okinawa Trough is the Iheya Graben. It is presently filled with onlapping IHG-A deposits (Fig. 28.4b, d). Such a "basin-filling" depositional configuration suggests that the depression structure of the Iheya Graben existed before the deposition of the IHG-A. On the other hand, the IHG-B deposits have shaped the base of the Iheya Graben with highlighted in yellow, and fault planes are shown with red lines. (e, f) Schematic of the two profiles based on the interpretations of the previous images. The thicknesses of the IHG-A deposits were measured from (c) and (d), while the height of the Iheya Ridge was estimated from high-resolution bathymetry data (Kumagai 2012)

inwardly rotated beds. The compressional "hinge" structures present in the IHG-B unit in the southern margin of the Iheya Graben (Fig. 28.4e, f) indicate that such rotations were formed by flexural subsidence of the IHG-B and its basement beneath. The cause of the flexure cannot be determined from the seismic data in this study however, magmatism in the region is the likely candidate. Previous study on crustal velocities in this region reported high-attenuation zone at $\sim 10 \mathrm{~km}$ beneath the sea surface, which could be interpreted as the lower crust with high thermal elasticity or melt content (Nagumo et al. 1986).

Both the northern and southern trough floors are flat-surfaced and extensively cut by listric faults (Figs. 28.2 and 28.3). 
Similarly, each section has a dip-reversal in the middle of the basin. The difference between the two parts is marked with whether the deposits have uniform inclination or not. This indicates that each section of the basin has experienced a different tectonic history. Kimura (1990) previously suggested that the center of older rift basin which was present before the Pleistocene, was at the western margin of the Okinawa Trough, based on his interpretations for seismic profiles. The highly inclined IHN-B deposits as well as the distinct faults geometry in the northern trough floor would be the remnant of such a past rifting activity.

\subsubsection{Age of the Iheya Graben Initiation}

The chronology of intra-trough "grabens" are thought to be important in determining the evolution of the Okinawa Trough. Kimura (2000) assumed that the "grabens" in the Okinawa Trough have formed since $1 \mathrm{Ma}$, although the detailed ages of each graben remain unknown. Because the flank of the Iheya Ridge overlies the IHG-A deposits and is almost exposed to the seafloor (Fig. 28.4d), the Iheya Ridge edifice must have formed after the Iheya Graben had been filled. Using K-Ar dating of basalt samples, Kimura et al. (1986) reported an age of $0.42 \pm 0.19 \mathrm{Ma}$ for the Iheya Ridge. Therefore, the initiation of the Iheya Graben formation and subsequent deposition of the IHG-A unit must have occurred before $0.2 \mathrm{Ma}$.

Submarine channels flowing into the Iheya Graben can be seen in the high-resolution bathymetry map (Fig. 28.1d). These channels occur at a depth of 1,550-1,650 $\mathrm{m}$ and cut the faulted seafloor of the Iheya Graben. Similar features are observed in the intra-trough Yonaguni Graben, located in the southernmost part of the Okinawa Trough, and occur at approximately same depth (Sibuet et al. 1998). However, the meandering channels observed in the Yaeyama Graben are cut by faults, unlike the un-faulted channels of the Iheya Graben. Through dives \#458-459, observations by remotely operated vehicle Dorphin-3 K, Kimura et al. (2001) determined that the channels in the Yonaguni Graben are presently not active because of the lack of erosional features on the surface, and hypothesize that they were formed in one of the glacial periods in the late Quaternary. They suggest the Riss Glaciation (0.2-0.12 Ma) was likeliest based on the previously known stratigraphic unconformities in the East China Sea. However, as previously noted, the depression of the Iheya Graben should be formed and filled with $200 \mathrm{~m}$ thick deposits prior to $0.2 \mathrm{Ma}$. Therefore, when it is assumed that they were formed together, both the channels in the Iheya Graben and the meander in the southern Okinawa Trough might be the products of an older, lower sea level. It also indicates that the Iheya Graben in the mid-Okinawa Trough is older, or less active than the Yaeyama Graben in the southernmost Okinawa Trough.

\subsubsection{Present Rifting Status in the Iheya Graben Area of the Mid-Okinawa Trough}

The present status of rifting-related tectonism in the Iheya Graben area can be evaluated through the propagation and displacement of faults. Despite abundant active listric and non-listric normal faulting throughout the Okinawa Trough, topographical displacements on the seafloor are clearly weighted along the Iheya Graben (Fig. 28.1). The poorly rotated recent IHN-A deposits in the northern trough floor basin indicate low slip rates because the abrupt change that marks the boundary of IHN-A and B occurred (Fig. 28.3). The listric faulting in the southern part of the trough on the other hand has not caused significant displacement (Figs. 28.1 and 28.2). Therefore, the active tectonics in the area may have been concentrated in the Iheya Graben because the Iheya Graben was initially formed with the rapid flexural subsidence. As the compressional faulting at the "hinge" area is not propagated into the upper IHG-A deposits, the flexural subsidence was thought to be an abrupt and short-lived activity. Instead, simple syn-depression normal faulting contributes to the latest growth of the Iheya Graben, as large displacements are exposed on the seafloor (Fig. 28.4).

\subsection{Conclusion}

The seismic reflection profiles in the Iheya Graben and adjacent areas of the mid-Okinawa Trough reveal geological structures that allow for the chronological ordering of events in the region. Extensive listric faulting in the thick deposits takes place throughout the flat-surfaced trough floor, although the rate of slip is presently negligible. The most recent major event in the area was the formation of the Iheya Graben, which was initiated with abrupt flexural subsidence followed by the growth with normal faulting. The age of the Iheya Graben is older than that of the Iheya Ridge, which is at least $0.2 \mathrm{Ma}$. The formation of the Iheya Graben and volcanism afterwards raise the possibility that the large-scale magmatism beneath the Iheya Graben is the present driving force of back-arc rifting in the region.

Acknowledgements This study was supported by the "TAIGA project," which was funded by a Grant-in-Aid for Scientific Research on Innovative Areas (No. 20109004) from the Ministry of Education, Culture, Sports, Science and Technology (MEXT), Japan.

The YK12-16 Cruise was conducted as a part of the Submarine Resources Research Project, JAMSTEC. Dr. H, Machiyama and 
Y. 'Nishio supported the survey as on-board scientists. Other seismic data we used in this study were also acquired by JAMSTEC.

We thank K. Okino (University of Tokyo) and M. Asada (JAMSTEC) for their constructive review comments. Our manuscript is well improved by their comments.

T. Tsuji gratefully acknowledges the support of the I2CNER, sponsored by the World Premier International Research Center Initiative (WPI), MEXT, Japan. T. Tsuji is also partially supported for this work by Sumitomo Foundation.

Open Access This chapter is distributed under the terms of the Creative Commons Attribution Noncommercial License, which permits any noncommercial use, distribution, and reproduction in any medium, provided the original author(s) and source are credited.

\section{References}

Furukawa M, Tokuyama H, Abe S, Nishizawa A, Kinoshita H (1991) Report on DELP 1988 cruises in the Okinawa Trough Part 2. Seismic reflection studies in the southwestern part of the Okinawa Trough. Bull ERI Univ Tokyo 66:17-36

Glasby GP, Notsu K (2003) Submarine hydrothermal mineralization in the Okinawa Trough, SW of Japan: an overview. Ore Geol Rev 23:299-339. doi:10.1016/j.oregeorev.2003.07.001

Iryu Y, Matsuda H, Machiyama H, Piller WE, Quinn TM, Mutti M (2006) Introductory perspective on the COREF project. Island Arc 15:393-406. doi:10.1111/j.1440-1738.2006.00537.x

Kimura M (1990) Genesis and formation of the Okinawa Trough, Japan. Memoirs Geol Soc Japan 34:77-88

Kimura M (2000) Paleogeography of the Ryukyu Islands. Tropics 10 (1):5-24

Kimura M, Kaneoka I, Kato Y, Yamamoto S, Kushiro I, Tokuyama H, Kinoshita H, Isezaki N, Masaki H, Oshida A, Uyeda S, Hilde T (1986) Report on DELP 1984 cruises in the middle Okinawa Trough. Part 5: topography and geology of the central grabens and their vicinity. Bull ERI Univ Tokyo 61:269-310

Kimura M, Kato Y, Tanaka T, Naka J, Gamou T, Yamano M, Ando M, Uyeda S, Sakai H, Oomori T, Izawa E, Kanenaga M, Ono T, Oshida A (1987) Submersible SHINKAI 2000 study in the central rift in the Middle Okinawa Trough. JAMSTEC Deepsea Res 3:165-196

Kimura M, Matsumoto T, Shinjo R, Nakamura M, Motoyama I, Machiyama H, Toyama G, Yagi H (2001) Meanders recognized in the southwestern part of the Okinawa Trough and its significance. JAMSTEC Deepsea Res 18:103-120

Kumagai H (2012) Yokosuka/Urashima "Cruise Report" YK12-16, JAMSTEC. http://www.godac.jamstec.go.jp/catalog/data/doc_cata $\log /$ media/YK12-16_all.pdf

Lee C-S, Shore GG, Bebee LD, Lu RS, Hilde T (1980) Okinawa Trough: origin of a back-arc basin. Marine Geol 35:219-241

Letouzey J, Kimura M (1986) The Okinawa Trough: genesis of a backarc basin developing along a continental margin. Tectonophysics 125:209-230

Miki M (1995) Two-phase opening model for the Okinawa Trough inferred from paleomagnetic study of the Ryukyu arc. J Geophys Res 100(B5):8169-8184. doi:10.1029/95JB00034

Nagumo S, Kinoshita H, Kasahara J, Ouchi T, Tokuyama H, Asamuma T, Koresawa S, Akiyoshi H (1986) Report on DELP 1984 cruises in the middle Okinawa Trough Part 2: seismic structural studies. Bull ERI Univ Tokyo 61:167-202

Otubo M, Hayashi D (2003) Neotectonics in southern Ryukyu arc by means of paleostress analysis. Bull Fac Sci Univ Ryukyus 76:1-73

Park J-O, Tokuyama H, Shinohara M, Suyehiro K, Taira A (1998) Seismic record of tectonic evolution and backarc rifting in the southern Ryukyu island arc system. Tectonophysics 294:21-42

Ryan BF, Carbotte SM, Coplan JO, O'Hara S, Melkonian A, Arko R, Weissel RA, Ferrini V, Goodwillie A, Nitsche F, Bonczkowski J, Zemsky R (2009) Global multi-resolution topography synthesis. Geochem Geophys Geosyst 10(3), Q03014. doi:10.1029/ 2008GC002332

Sibuet J-C, Letouzey J, Barbier F, Charvet J, Foucher J-P, Hilde T, Kimura M, Ling-Yun C, Marsset B, Muller C, Stephan J-F (1987) Back arc extension in the Okinawa Trough. J Geophys Res 92 (B13):14041-14063. doi:10.1029/JB092iB13p14041

Sibuet J-C, Deffontaines B, Hsu S-K, Thareau N, Le Formal J-P, Liu CS, ACT Party (1998) Okinawa trough backarc basin: early tectonic and magmatic evolution. J Geophys Res 103(B12):30245-30267

Tsuji T, Takai K, Oiwane H, Nakamura Y, Masaki Y, Kumagai H, Kinoshita M, Yamamoto F, Okano T, Kuramoto S (2012) Hydrothermal fluid flow system around the Iheya North Knoll in the midOkinawa trough based on seismic reflection data. J Volc Geotherm Res 213:41-50. doi:10.1016/j.jvolgeores.2011.11.007

Ueda S, Kimura M, Tanaka T, Kaneoka I, Kato Y, Kushiro I (1985) Spreading center of the Okinawa Trough. JAMSTEC Deepsea Res $1: 123-142$

Zang SX, Chen QY, Ning JY, Shen ZK, Liu YG (2002) Motion of the Philippine Sea plate consistent with the NUVEL-1A model. Geophys J Int 150(3):809-819 